This is an electronic reprint of the original article. This reprint may differ from the original in pagination and typographic detail.

Author(s): Virkki, Tuija

Title: $\quad$ Social and health care professionals' views on responsible agency in the process of ending intimate partner violence

Year: $\quad 2015$

Version:

Please cite the original version:

Virkki, T. (2015). Social and health care professionals' views on responsible agency in the process of ending intimate partner violence. Violence Against Women, 21(6), 712-733. https://doi.org/10.1177/1077801215577213

All material supplied via JYX is protected by copyright and other intellectual property rights, and duplication or sale of all or part of any of the repository collections is not permitted, except that material may be duplicated by you for your research use or educational purposes in electronic or print form. You must obtain permission for any other use. Electronic or print copies may not be offered, whether for sale or otherwise to anyone who is not an authorised user. 
SOCIAL AND HEALTH CARE PROFESSIONALS' VIEWS ON RESPONSIBLE

AGENCY IN THE PROCESS OF ENDING INTIMATE PARTNER VIOLENCE

\author{
Tuija Virkki
}

Department of Social Sciences and Philosophy, University of Jyväskylä, Finland

E-mail: tuija.virkki@jyu.fi

Contact information:

P.O. Box 35

40014 University of Jyväskylä

Finland

FUNDING: The research has received funding from the Academy of Finland (grant number: 138506)

KEY WORDS: intimate partner violence, responsibility, violence intervention

This manuscript is scheduled to be published in the May issue of Violence Against Women (v. 21, \#5). In addition, it will be published online ahead of print (early view). 


\begin{abstract}
This article examines social and health care professionals' views, based on their encounters with both victims and perpetrators, on the division of responsibility in the process of ending intimate partner violence. Applying discourse analysis to focus group discussions with a total of 45 professionals on solutions to the problem, several positions of responsible agency that the professionals place themselves and their clients in are identified. The results suggest that one key to understanding the complexities involved in violence intervention lies in a more adequate theorization of the temporal and intersubjective dimensions of the process of assigning responsibility for the problem.
\end{abstract}


Intimate partner violence (IPV) - defined as abuse that occurs between two people in close relationship - is a serious social problem that affects individuals, families, and communities in various ways. Apart from deaths and injuries, IPV is associated with a number of adverse health outcomes, and various psychological and social consequences for its victims (Black, 2011; Rivara et al., 2007). Recognition of the injurious effects of IPV raises the question of what can be done to diminish the problem of IPV and whose responsibility is it to solve the problem. Because IPV increases the need for social and health care services, it has been suggested that professionals in these fields are in a key position when it comes to helping victims (Dutton et al., 2006). In addition, there has been a call for attempts to tackle the problem of IPV by providing treatment for perpetrators and so called batterer intervention programs in the social and health care domain (Shamai \& Buchbinder, 2009).

This article examines social and health care professionals' views on the question of responsibility in the process of ending the cycle of IPV. Previous studies suggest that health and social care providers' attitudes towards IPV and understanding of their own role in violence intervention have an important effect on their willingness to deal with the problem (Robinson, 2010; Husso et al., 2011). Attitudes towards IPV are formed by a wide range of social processes at multiple levels of the social order, and these societal attitudes also shape the formal responses of professionals and institutions to the problem (Flood \& Pease, 2009). Several studies have identified socially and culturally derived attitudes that portray IPV in ways that stress the notions of personal responsibility and individual action (Leisenring, 2006; Baly, 2010). In these approaches, IPV is not only portrayed as a private problem, but most often also as the victims' problem - and they have the responsibility for solving it.

Research has identified several stereotypical beliefs that hold the victim responsible for the abuse, exonerate the perpetrator, and minimize the seriousness of the problem (Yamawaki et al., 2012). Taken together, such myths are thought to reduce social support for victims by 
transforming them from innocent victims of a potentially lethal crime to individuals who have chosen to be battered. According to these myths, the victims are not really victims because they could have avoided the abuse or probably provoked it. Far from being absolved from responsibility for their own victimization, victims are blamed for their role in their abuse (Berns, 2009).

In this way, an ethos of blame contributes to a culture in which IPV is normalized, sustained, and accepted as the default situation (Thapar-Björkert \& Morgan, 2010). These approaches focus on the victims' responsibility for solving the problem while ignoring not only the role of the abuser but also that of society. It is suggested that these approaches enable society to absolve itself of any collective responsibility for tackling IPV. The blaming of the victims of IPV by professionals remains an issue that needs to be properly addressed (Fox \& Cook, 2011). Despite the extensive literature on attitudes that blame the victims and make them responsible for ending the abuse, there appears to be a need for a more profound investigation into the ways in which social and health care professionals see the division of responsibility in stopping the vicious cycle of IPV.

In this article, I look at social and health care professionals' views, based on their encounters with both victims and perpetrators, on the division of responsible agency in ending IPV. I am not concerned here with the responsibilities of institutions or society at large; instead, I am concerned with the attribution of responsibility to individuals in the triadic relationship between professionals, victims and perpetrators. I examine how professionals see the role of victims and perpetrators, and their own role in the process of ending IPV. How do professionals place themselves and their clients as responsible agents, when they discuss solutions to IPV?

The first aim in this article is to provide answers to these questions based on discourse analysis of empirical data. The data comprise ten focus groups with a total of 45 professionals 
in various social and health care units in Finland. The second aim is to offer novel conceptualizations of responsible agency for use in violence research. I introduce the concepts of retrospective and prospective responsibility, and emphasize the importance of prospective responsibility in violence intervention.

\section{CONCEPTUAL CONSIDERATIONS}

The concepts of responsibility and agency are central to research on IPV and violence intervention. By "agency", I refer to one's ability to make choices and to take responsibility for one's actions. Agents are persons whose lives are attributable to them as something they conduct, not just as something that occurs (Watson, 2004). Thus, agency is central to the production and management of responsibility. The possibility of choice can be seen as a presupposition for the attribution of moral responsibility, based on an understanding of rights and duties, right and wrong.

However, in spite of emphasizing the significance of choices as a basis for responsibility, I am not subscribing to individualized or voluntaristic notions of responsible agency. The voluntaristic notion of free will is based on the concept of a human being as a rational individual capable of making choices uninfluenced by other people (Barnes, 2000). In my study, the concept of responsible agency is an inherently social notion: it is mainly about interpersonal normative standards of conduct that create expectations between members of a shared community. In addition, I situate the understanding of responsible agency within a social constructivist paradigm, which regards responsible agency as a discursive phenomenon (Harré, 1995). Strictly speaking, the subject under study in this article is not the responsible agency of an individual professional or a client, but the ways in which professionals see and construct the issue of responsible agency. 
Barnes (2000) maintains that researchers need different conceptions of responsible agency in different circumstances. In my research, the emphasis is on studying the responsibility for ending IPV, which is the ultimate goal of violence intervention work. To achieve this goal, it is less a matter of identifying the "guilty parties", but rather of finding means for change and supporting actions that would prevent future victimization. Violence intervention work is future oriented, which has several implications for the conceptual choices in this study. During the data analysis, there emerged a need to seek conceptualizations that would (1) deal with the difference between blame and responsibility, and (2) take into consideration the temporal dimensions of responsible agency. Because such a study has not been conducted in violence research so far, I sought these kinds of conceptualizations in health care ethics (e.g., Kelley, 2005; Turoldo, 2009), from which I borrowed the concepts of retrospective responsibility and prospective responsibility.

These conceptualizations place responsible agency within a specifically temporal framework. What we mean by responsibility depends, in large part, on whether we are facing forward or looking backward. In my article, the most important dimension of responsible agency is the projective element which encompasses the consideration of future trajectories of action. I am concerned mainly with prospective responsibility (responsibility for future occurrences), and not so much with retrospective responsibility (responsibility for past occurrences). Roughly stated, retrospective or backward looking responsibility implies a particular evaluation of what has happened, and it is retributive; it is about culpability, assigning blame, figuring out who caused the present state of affairs (Kelley, 2005).

Whereas retrospective responsibility is strongly tied to the concept of blame, prospective responsibility is free of such associations (Turoldo, 2009). The conceptual difference between blame and responsibility is based on the separation of the responsibility for the problem from the responsibility for the solution (Powers, 2003). Prospective or 
forward-looking responsibility is about taking responsibility for present actions and future consequences. To attribute this kind of responsibility to someone is equivalent to saying she has an obligation to do something. Through this attribution, an attempt can be made to guide and change the individual's behavior. This use of the notion of responsibility encourages preventive responsible behavior in the hopes for avoiding bad consequences and, hence, has primarily an educational and motivating function - all issues substantive in violence intervention.

\section{METHOD}

\section{Data}

The total data corpus of this study consists of ten focus group interviews (the total number of participants $=45$ ) in various social and health care units in Finland. Data cluster 1 consists of four focus group interviews with 15 participants. The data were collected in 2012 for the Couples Counseling as a Means of Preventing Intimate Partner Violence -project (20092012) carried out at the University of Jyväskylä. This project examines IPV-related issues faced during counseling, especially couples counseling sessions, in various contexts of institutional help and counseling for domestic violence. The informants who participated in these interviews were family counselors, social workers, therapists, crisis workers and psychologists by profession. The interviewees mostly worked in crisis centers, family counseling centers, mother and child homes and shelters, in associations for mental health, and treatment centers specialized in treating alcohol and drug addictions through outpatient care. Some of the interviewees have years of experience in violence intervention in particular, and all of them constantly face questions of IPV in their work. The majority of the interviewees encountered both victims and perpetrators of violence in their work. However, some of the interviewees worked only with the perpetrators, some only with the victims. 
Data cluster 2 was collected for a development and research project Violence Intervention in Specialist Health Care, funded by the EU Daphne III Program in 2009-2010. The data consist of six focus group interviews collected in 2009 in Jyväskylä, Finland. In these interviews specialist health care personnel discussed how they encounter and intervene in domestic violence. The total of 30 participants comprised nurses, physicians, social workers and psychologists working in various special health care departments (e.g., emergency department, maternity and psychiatric ward) in Central Finland Health Care District. The majority of the interviewees reported encountering victims of IPV in their work. None of the interviewees were specialized in violence intervention work, although some of them had been on a course dealing with the issue of victimology.

The focus groups were led by the researcher and the research assistant. The interview questions concerned the ways in which participants perceive their own role and possibilities for action as professionals encountering problems related to domestic violence. The most usual example of domestic violence in these focus group interviews was IPV, and was mainly violence against women in heterosexual relationships. Each interview lasted roughly one and a half hours, and all the interviews were audio and video recorded and transcribed word for word.

This study was approved by the ethical board of the Central Finland Health Care District. Confidentiality and anonymity were maintained by removing all identifiable references to the focus groups and the interviewees from the transcribed texts. Details of the units in which the professionals worked are deliberately withheld to further protect anonymity. In the cited texts, $G$ refers to the group and $\mathrm{P}$ to the participant.

Analysis

In this article, I am interested in the social construction of responsible agency in a wide range of contexts of social and health care in which professionals deal with the problem of IPV. I 
apply methods of discourse analysis, which considers how language constructs - not merely reflects - socio-cultural perspectives, subjectivities and identities (Gee, 2010). Discourse analysis is about analyzing talk and other forms of discourse. Like other qualitative analytical approaches, discourse analysis is not a unified, unitary approach. It consists of many theoretical approaches to studying the use of language in various contexts of social life. For the purposes of my study, positioning theory (van Langenhove \& Harré, 2003) offers a useful tool for analyzing constructions of responsible agency. Positioning can be defined as the way in which people dynamically produce and explain the everyday behavior of themselves and others. In the course of the interaction various descriptions and categorizations are used, and it is with these discursive constructions that individuals create for themselves and others subject positions where different rights and responsibilities are attributed to them.

The main questions in my analysis are: (1) What are the main discourses in regard to the issue of responsibility for ending the vicious cycle of violence?, (2) What positions of responsible agency are made available to the actors in each discourse?, and (3) How is responsibility divided between the different agents in the different discourses? In the first stage of analysis, I read the transcripts multiple times in search of discourse patterns, particularly for how the professionals positioned themselves and their clients in relation to the problem of IPV. The aim was to find common features in the view of agency and the placement of agents on the continuum between responsibility and non-responsibility. After I had identified the different discourses, I labeled them and took a closer look at their similarities and differences. As the temporality of responsible agency emerged as a salient theme, I returned to the data to complete the final analysis on the basis of these conceptual refinements. 
In my analysis, I identified and labeled four different discourses in the interviewed professionals' speech: (1) making the victim responsible, (2) empowering the victim, (3) making the perpetrator responsible, and (4) educating the perpetrator. Each of these discourses places the agents in them in different positions that are constructed in relation to each other. In IPV, one of these relations is that between the perpetrator and the victim. However, this relationship is rarely taken up in professional discussions on the topic; instead, the focus is more on the relationship between, on the one hand, the positions of the professional and the victim, and, on the other hand, the positions of the professional and the perpetrator.

I now take a closer look at how the professionals studied here constructed responsible agency for ending IPV in their talk about (1) their work with the victims of violence and (2) their work with the perpetrators. When talking about responsible agency in relation to victims' and perpetrators', the professionals simultaneously placed themselves and their clients in the complementary subject positions made available within each discourse.

\section{$\underline{\text { Victim's Responsibility for Solving the Problem }}$}

In their work, professionals in specialist health care mostly encounter victims who have sought care for their injuries, and seldom meet the perpetrators. When considering the topic of responsible agency, the professionals tended to underline the victims' responsibility for solving the problem of IPV:

G1P4: It's like treatment for high blood pressure, like if you can stand the buzzing in your ears then just leave it alone, and die younger. It's your own choice. People must do something about it themselves, that's where it starts from. 
Discourse that makes the victim responsible places the victim in a subject position, in which the individual's own choices are central. In layman's terms, the basic assumption underlying agency is that individuals make choices of their own free will and are responsible for their actions (Barnes, 2000). Thus, the perception is that victims have chosen violent people as partners, and also, of their own free will, have chosen not to set limits to violent behavior and not to leave the violent relationship. Previous research has shown that, in public discussion on IPV, the victims of violence are to blame for the violence and its consequences (Berns, 2009). In line with the terminology used in the present article, it can be said that blaming the victim places her in a position of responsible agency in a retrospective framework that evaluates past events and their consequences.

In my data, explicit blaming the victim in this way was quite rare, and recent studies on the topic indicate that this attitude is gradually vanishing from public discourse as well (Leisenring, 2006). However, it seems that the notion that the victim is responsible for solving the problem lingers on. Although victims are not directly blamed for the violence, they are often held responsible for ending the violent relationship. I term this manner of attributing responsibility to the victim prospective, that is, a future-oriented way of making the victim responsible. This approach implies that the victim should act in a more responsible way in the future. At the same time, it implies that she has the ability and competence to make rational choices about her life.

In addition, many focus group discussions place the victim of IPV in the position of an independent and autonomous individual, who has the right to decide on matters concerning her own life. This approach regards IPV as a private question, as something that the "outsiders" have no right to intervene in, and thus aims at protecting individual freedom and privacy (see also Kulkarni et al., 2010). According to the specialist health care professionals interviewed here, asking about IPV may be interpreted as an insult by the client and, therefore, 
taking this question up has to be left to the clients themselves. Even in cases when the client has brought up IPV, and there are visible signs of violence, the basic perception is that the client has the freedom and the responsibility to decide whether the matter will be taken any further. The professionals are then left with simply offering the client an opportunity to receive help, if there seems to be a definite need for it:

G4P4: I think that people should have an opportunity to look for a place to get the information from and then, based on that info, they should all be able to think for themselves. In this way the patients become active themselves.

The professional's subject position is constructed in relation to the autonomous subject position assigned to the victim. Placing the victim in the position of an independent and autonomous agent underlines the victim's right to act according to her own free will in matters concerning her life, which then limits the professional's right to intervene in IPV. Given that respect for the autonomous choices of patients runs deep in modern health care, there are reasons to value the claim that competent and well-informed individuals are the best interpreters of their own interest and that they should be free to make choices others would regard as non-beneficial to them. Professionals have no right, in either the moral sense or in practice, to influence their clients' decisions, even when they seem wrong and harmful: "We can't help anybody against their will, if that person doesn't want to be helped."

This is partly a question of trying to protect patient rights and patient choice, and also an attempt to break free from the medical paternalism that has been criticized as old-fashioned (Kelley, 2005). Sometimes, however, it seems that this is also a question of the professionals trying to avoid control when working with victims of IPV:

G5P2: Somehow I feel like I should try to persuade or encourage them to seek help, but to tell them to do so is bit difficult. 
G5P4: There's the problem of control, like, who uses power in a situation in which the person has already been controlled.

G5P5: Then there's the problem of relations of dependency. For example, if it's religion that forbids divorce, then how much can we intervene in that person's own right to be who and what she is, if we request her to take the offered help. I mean, the most important thing is that we offer help, and she gets to choose.

In addition to respecting the victim's right to autonomy, other essential characteristics of the discourse on making the victim responsible are views on the victim's abilities and competencies that are implicitly included in the right to autonomy. The voluntaristic notion of free will is based on the concept of a person as a rational individual capable of making choices without being influenced by other people (Barnes, 2000). Such an individual is seen to possess an innate or a learnt ability to consider different options in her life and to make rational choices on that basis. However, this assumption of equal possibilities and abilities to act does not take into account particular contexts or the impact of the individuals' environment on their abilities and opportunities to act.

Constructing victims of IPV as rational and autonomous individuals is far from unproblematic. In their discussions, the professionals spoke about their having to work with the contradiction that emerges when the victim's acts and behavior seem irrational and selfinflicting. One of the most typical examples given to describe this kind of a situation is that of the victim who returns to her violent spouse. From the point of view of responsible agency, which highlights the victim's individual competence and rationality, these victims' actions seem incomprehensible. It provides no means for understanding how being a victim of IPV influences people's ability to act - or their possibilities for acting. This contradiction creates confusion and denial: 
G6P1: Well, the biggest obstacle to doing this job is one's own feelings and cynicism and frustration. We have no means for involuntary commitment, so there she goes, back to being battered again. I can't do anything about it. They provoke feelings and then you have this feeling of denial, like, I can't deal with this. What can you do, as a professional, other than "well you made your own choice."

Expectations concerning the agency of victims, and subsequent disappointments resulting from unfulfilled expectations, create feelings of frustration in professionals. While explicitly attributing blame to the victims is more uncommon today than earlier, a tendency to focus on a woman's decisions to leave or stay in abusive relationships remains evident (Leisenring, 2006). According to Dunn and Powell-Williams (2007), professionals working with victims consider ending a violent relationship the most significant and often the only solution to the vicious cycle of violence, and making this decision is placed in the hands of the victims. It is the victims, not their abusers, whom the professionals expect to make the changes, and the only choice they see as appropriate - the only acceptable agency for a victim - is leaving the violent relationship. Indeed, there is a tendency to overemphasize the choices available to the battered woman, thereby underestimating the constraints they face as victims of IPV. If victims fail to leave an abusive relationship, they are often seen as ultimately responsible for the future violence they may experience.

\section{Understanding Victimization and Aiming at Empowering the Victims}

My data also include examples of discourse that aims at a nonjudgmental understanding of the victims of IPV and the constraints on their ability to act. This kind of discourse was common among the professionals who were specialized in working with victims. The professionals in specialized health care, who had received training in working with victims of IPV, also 
explained that they saw a need for better understanding of what it means to be a target of violence:

G6P6: It's sometimes difficult for the personnel to understand why she always goes back there, where the guy keeps beating her up. Because a dependent relationship is like that, it's not at all easy for us to understand why it's so difficult to withdraw from the relationship, and why it's always easier to go back to the violent relationship.

In the group discussions many structural, practical and psychological reasons were brought up for difficulties in detaching oneself from a violent relationship. Many of the professionals also stated that victims often do not even see themselves as targets of violent behavior. According to two professionals working in violence intervention:

G7P4: Our role is to be active, to be there to see, what their life is like and what the most acute problem in need of intervention is. Violence blurs the line between what is right and what is wrong. The target of violence is quite lost, she can't see it. G7P2: We must see how the consequences of violence and traumatization manifest themselves in this victim, and how her behavior is not necessarily that voluntary.

The discourse on victimization places victim in a subject position, in which her responsible agency is seen as limited. The professionals expressed understanding of the constraints being the target of IPV imposes on the individual's freedom to choose, the autonomy of her action and her self-determinacy. The dependency created by IPV, as well as other effects caused by it were considered to reduce the victim's opportunities and ability to act, and therefore, the victim cannot be expected to act according to the theory of responsible agency like others.

G3P3: The more unable the victim is to look after herself, the greater the responsibility and the duty we should have to look after her. 
Understanding the dynamics of victimization places the professionals in a subject position that is more active and responsible than it is in the cases discussed above. While the victims are constructed as "ignorant" and "non-understanding", the professionals position themselves as the more knowledgeable and skillfully competent agent. In this discourse, the task of professionals is to make the victims realize their own situation:

G10P3: Very often we notice that the clients themselves don't even see the violence, or at least, for a long time they have not understood what the problem is. As a professional you then try to wake them up to see what's going on.

Raising victims' awareness and increasing their level of understanding is considered a precondition of efforts to empower them. The existing research findings highlight the importance of fostering a sense of empowerment when intervening in the case of battered women (Kulkarni et al., 2012; Perez et al., 2012). In my data, the professionals' discourse on empowerment means locating the victim's resources and strengths, and increasing her ability to act and her control over her life. Empowering is a process, during which the victim is supposed to change from a passive victim of circumstances to an active agent with power over her own life. According to Busch and Valentine (2000), the empowerment perspective maintains that battered women are not victims by choice, and that given adequate support, they will choose violence-free lives for themselves. For battered women, empowerment belief means to beginning to take responsibility for their future by actively attempting to change their situations.

Professionals have a central task in this empowerment process: they help the victim to help herself, and thus, to take responsibility for her own life. In the focus group discussions the professionals saw their role in the following way: 
G4P5: The victim's mental resources aren't at the moment such that she could change, so it's our task to build those mental resources for her so that she can then help herself. To support her in those things we can, and give her the help she needs, so that she gains the strength to change. We activate her support networks, so that at some point she will get the help she needs, and empowerment will take place, and she'll be able to break the vicious cycle of violence.

In the empowerment discourse, the professional's and the victim's subject positions are constructed in relation to each other: the professional helps the victim to see the problem, to find the strength to change and to create possibilities of action. The empowering discourse positions the professional as an agent who activates the victim's agency. In this process of activation, the victim's restricted agency will gradually change into responsible and active agency. However, the professional is the one initiating this process, and is the primary agent helping the victim to learn the expected agency. Ideally, empowerment prevents paternalism and promotes client choice; but in practice, the empowering process is defined and guided by the professional, and it engenders the type of agency expected by both the professional and the wider surrounding society.

According to my informants, one of the goals of the empowering process is to create an agent, who is capable of defending herself and setting limits to violence:

G9P3: One example occurs to me, in which violence had been a secret in the family for a very long time. I think it was a great victory that after a couple of years we had spent working with this woman, she gained the strength to defend herself and set some limits to this man. I believe that this woman became so empowered that the man was more or less either forced to accept it or to leave the family. 
Sometimes the main goal is to provide women with a potential means of controlling violence in their lives and preventing future victimization. However, the professionals' working with violence intervention pointed out that in many cases the only way to break the cycle of IPV is to put an end to the violent relationship. These informants spoke about their role in this process as that of "assisting the victim of violence to break free." In the group discussions the professionals working with violence intervention were asked about their experiences of successful client cases. One informant stated:

G9P4: When somebody gets rid of long-term violence, then that in itself is an experience of success, even if we have not been able to change the relationship or help the couple to live together. It's more about supporting one of the partners in breaking up with the other one, supporting one of them to become independent and empowered.

In these cases, the professional has an important task in helping the victim to decide on the question of divorce and then, once the decision has been made - by the victim herself, of course - to help her go through it. In the same way as the discourse that makes the victim responsible, the empowering discourse stresses that ending the violent relationship is ideally what the victim will opt to do. It has been noticed in research literature that despite the fact that there is more sympathy for victims and attempts to honor all the choices they make including staying - victims are still expected to choose ending the relationship (Berns \& Schweingruber, 2007). The cultural narrative about victims includes an "understanding" of why it is hard to leave, and yet a belief that victims need to leave.

The professionals' way of focusing on the victims' hoped for responsible agency is part of an approach to IPV that continues to center on the victim's responsibilities instead of those of the perpetrator, when discussing solutions to the problem. In much the same way as the discourse that makes the victim responsible for the violence against her, the empowering 
discourse underlines the victim's agency and responsibility. However, the question is no longer one of retrospective responsibility, but one of prospective, future-oriented responsibility. Although the empowering discourse manages to avoid blaming the victim for violence against her and its consequences, and it manages to provide us with some understanding of the victim's limited abilities to act, it nevertheless, in the end, makes the victim responsible for ending the violence against her.

According to Berns (2009), the main problem in the victim empowerment approach is that it focuses only on the personal level of empowerment. Basically, the overall goal of empowerment should include social justice and a reduction in social inequality. In the individualistic frame of reference of violence intervention, however, power is defined as a personal choice while ignoring the political and social dimensions of power as well as the cultural and structural context of IPV, the majority of which involves men's victimization of women. It has been claimed that the empowerment discourse leaves out the male abuser and the gendered nature of power differences, and thus empowerment becomes solely about what battered women do or do not do (Thapar-Björkert \& Morgan, 2010). Consequently, the victim is considered to be the party who has to change her life and adapt to the situation; the one who has to find a solution to problems that are seen as her own.

\section{Making the Perpetrator Responsible}

Making perpetrators responsible for their actions comes up as a topic particularly in the group discussions with professionals working in violence intervention. In the specialized health care professionals' group discussions the notion of making the perpetrators responsible for their actions either did not come up at all or it was mentioned as an impossible task because, as the professionals saw it, they could not start naming people responsible for violence. 
While professionals in specialist health care tend not to take sides, professionals working in violence intervention take it as their legitimate point of departure, if not their duty, to examine the question of who is responsible for violence. Taking responsibility was seen as a necessary starting point for working on the problem, and in particular, an important precondition for couples counseling, which includes working with both the victim and the perpetrator:

G9P2: It's essential that the perpetrator realizes that he's acting in a way that is wrong. G9P4: The perpetrator has to say it out loud and admit that he has behaved violently, so that it's not just something that comes up during the sessions, something that he merely listens to. So that he can really take responsibility for it.

G9P3: That must be the first precondition, that he takes responsibility, and does something about it, works with it.

As noted in studies on treating partner-violent men (Lawson et al., 2012; Shamai \& Buchbinder 2009), violence intervention work must target battering men's attributions of responsibility and change them. Research (Henning et al., 2005; Stosny, 2005) has revealed that perpetrators use various excuses, justifications, rationalizations and explanations in order to minimize violence or to deny responsibility for their violence and to project responsibility for violent episodes, as well as for solutions, onto others. Even in cases where perpetrators accept partial responsibility, they tend to blame external stressful situations and other people's conduct or internal, unstable, specific, unintentional and unavoidable situations caused by alcohol, drugs, frustration, anger or lack of control (Wallach \& Sela, 2008). It has been shown that the use of violence is constructed as a position of limited agency: perpetrators often distance themselves from an active agency concerning IPV by refusing to see violent behavior as a choice (Partanen et al., 2006). 
Effective intervention strategies require professionals to actively shift responsibility back to the perpetrators. In the discourse on making the perpetrator responsible, it is seen as the professional's task to demand that the abuser takes responsibility for violence, in both in the retrospective and prospective sense. In the discussions on responsibility in a retrospective sense, the perpetrator is positioned as the responsible ("guilty") agent, who realizes that violence is actually a choice, and thus, takes responsibility for his previous violent behavior. When discussing responsibility in a prospective sense, the perpetrator is positioned as an agent who will take responsibility for his actions and commits himself to refrain from violent behavior in the future.

Professionals have various means of making people responsible for their future behavior either voluntarily or via coercion. Some professionals make their clients sign written contracts, in which the client agrees to avoid the use of violence. If clients continue their violent behavior in spite of the agreement, the care or therapy relationship is withheld. The thinking that is based on non-violence contracts subscribes to the notion that citizens are capable of weighing different options rationally, and making conscious choices (Sulkunen, 2010). Although the idea of an individual, who enters into agreements seems to position the perpetrator as an agent who executes his own free will and makes his own choices, coercing the abuser to sign a contract or using the agreement as a precondition for beginning therapy in the first place introduces an element of compulsion into violence intervention work. Many of the professionals working in violence intervention criticized the use of contracts as a means of control, as these do not necessarily further the process of ending IPV:

G9P2: But very often it turns out that after a few sessions violence has come back to the picture, and the work ends there. Of course we need some control, but we should find other tools that would be more useful in that endeavor. 
G9P4: It's important to create a kind of a counseling relationship at first, so that the participants are motivated and join the process. On the one hand, the question of responsibility and making people responsible for their actions must be there from the start, but on the other hand, it is important to create a good counseling relationship, too.

Coercing perpetrators into signing an agreement on non-violent behavior puts professionals into a strong position in relation to their clients. However, professionals fear that pushing too hard will drive clients away. In addition, they feel that compulsion and control cannot create real changes in people's behavior. Making clients' responsible for their actions in a prospective sense calls for special skills; it requires that professionals have the ability to truly motivate their clients to change:

G7P4: The men often come here involuntarily, they wouldn't want this. It has to happen at their pace, so that the men become motivated and stay.

The discourse on making the perpetrator responsible in prospective sense includes the assumption that the client is motivated and willing to break the cycle of IPV. Thus, a superficial and instrumental commitment to violence intervention, based on force, is considered an inherent risk in violence intervention work. The informants point out that for some clients this work is just a game:

G10P4: We have some cases where the wife is in a women's shelter, and then the man comes to us to work on the problem, and we have to figure out what the real motive for the change in his behavior is. Is it merely to get his wife out off the shelter, to get her to move back home? Some of them are just acting the part. 
The act of joining the process of violence intervention does not, in itself, tell us whether the abuser's motive is a genuine desire to take prospective responsibility for his violent behavior or a mere instrumental attempt to keep the family together. The making of an agreement, in particular, is based on the economic notion that people are individuals who make rational choices and set their goals in rank order according to the benefits at stake (Sulkunen, 2010). Such policing on one's motives may lead perpetrators to take "pseudo responsibility" or "rhetorical responsibility" (Schrock \& Padavic, 2007) instead of truly acknowledging responsibility for their acts. The egoistic maximizing of one's own benefits at the costs of the others' wellbeing is naturally not the kind of ethical and responsible agency that violence intervention work aims at generating.

In addition to the centrality of genuine motivation and commitment of the perpetrators, both forms of responsibility assume that an agent has specific abilities and competences. An agent, who takes retrospective responsibility, must be able to interpret his past actions and to understand that they are morally wrong. The abuser's ability to understand what his actions mean to the victim is seen as the precondition for taking this kind of responsibility:

G10P3: I've been in couples counseling sessions where the man has taken responsibility for his violent behavior and has wanted to change his own behavior. In these sessions he has had to listen to his spouse's suffering and stories about injuries that have required surgery. He has realized in a completely different way what his violence has meant to this woman. In this way he has attained compassion and an understanding of the situation.

Studies on the topic support the notion that a successful process of taking responsibility presupposes the abuser's ability to feel a particular kind of compassion (Scott \& Wolfe, 2000). In addition, it is essential that the abuser "realizes that this kind of action is not right", as one 
of the participants put it in the group discussion. Thus, the position of a responsible agent includes the ability to feel compassion and achieve ethical understanding and, based on these, a genuine motivation and desire to change. Although the professional's role as the motivator for taking responsibility is central at the beginning of the process, as the process advances the abuser's role in taking prospective responsibility and his willingness to commit himself to the process become increasingly important.

The IPV interventions stress the competence of the perpetrator as a social actor aware of the morally reprehensible character of his acts, and the continuity of his responsibility across situations. This makes it possible to treat perpetrators as capable of active agency and autonomy, and even more of intentionality, which is a central feature of the discourse on making the perpetrator responsible. Intentionality means an active attitude towards the world and, in particular, to the future (Bratman, 2007). On this view, intentional subject can rise above immediate his impulses, and project himself into other possibilities of acting.

\section{Educating the Perpetrator to Non-Violent Behavior}

In the discourse discussed above, which aims at making perpetrators responsible for their actions, the role of the professional in violence intervention was defined as that of one who demands and motivates the abuser to take responsibility for IPV that has already happened as well as make a future commitment to non-violent behavior. The discourse on educating abusers, in turn, aims at increasing abusers' competence to control their behavior, and thus it is more future-oriented.

Many of the programs targeted at intimately violent men can be defined as educational therapeutic groups (Lawson et al., 2012). Most of these programs utilize psycho-educational or cognitive-behavioral philosophy, which both share common treatment-related targets: beliefs, personal responsibility and behavior change. The primary focus is on relationships 
skills training, anger management and distorted beliefs that lead to IPV. According to my informants, the counseling of perpetrators focuses on couching the abuser to control his own behavior, which usually takes place as an individual training prior to the couples counseling: G7P2: People are trained for couples counseling, like coached in the use of various methods of self-control.

G7P4: So the coaching is about a kind of self-control in the relationship. These men often have traumas, too, so it would help if they could somehow control the situation and had a means to keep their emotional reactions under control, and learn constructive ways of expressing their feelings.

When discussing couples counseling professionals brought up the couple's need to learn shared ways of communication, in addition to the need to educate the abuser. Thus, the focus of the work is not merely on the responsible agency of the abuser, but also on constructing shared responsibility for the couple:

G9P2: We have gone through matters concerning the expression of aggression and solving contradictions, like how people can argue so that one doesn't harm the other physically or mentally. When we have gone through some concrete ways and methods, they have realized that they really can learn another way of solving their problems. And during follow-ups we have noticed that this new way of solving problems has developed further.

G9P4: Particularly if the relationship is relatively new so that we can have an impact on it through a psycho-educative approach. They acquire some information on how to solve contradictions. 
According to McCollum and Sith (2008), couples treatment for IPV remains a controversial issue. The tendency in couples treatment to develop ways to both hold violent partners accountable and examine couple interaction has led to fears that, instead of the partner-violent man being held squarely responsible for his actions, his responsibility may evaporate in discussion of couple interaction patterns, conflict resolution skills and other matters that comprise couple therapy. By looking at IPV in an interactional framework, there is a risk that women will be put in the position of having to control not only their own behavior but also their partner's violent behavior, of which they are a victim. In particular, the feminist sociocultural approach has criticized the use of therapeutic theories, which often explain IPV as a problem of couple interaction, personality disputes or men's traumatization (Partanen et al., 2006). The feminist orientation sees IPV as an abuse of power aimed at maintaining patriarchal structures. Consequently, the target in the feminist approach is to educate partnerviolent men to change their oppressive beliefs and attitudes towards women and to take responsibility for their violence.

While some of the professionals in my data express awareness of the social context of IPV and, in particular, gender domination, the main focus in the group discussions is on the psycho-educational approach. Professionals see it as their task to help abusers to create the competencies and abilities needed for responsible agency, especially in the sense of prospective responsibility. Very often this is a question of the professionals providing their clients with various means (e.g. taking time-out) of controlling their behavior, which the clients then apply to their own lives:

G8P2: Well, there are many ways of doing time-out, because counting to ten doesn't do the trick for everybody. It can be something that stops the abuser to think for a while, instead of acting immediately. 
The research on programs for partner-violent men reveals that the most important personal change in therapy is the acquisition of self-control and the ability to make non-violent choices (Shamai \& Buchbinder, 2009). In addition, it has been noticed that the professionals are assigned a powerful position in producing the change, as they are perceived as having the knowledge to solve the problem. In my data, the educating discourse underlines the professional's position as the instructor of the abuser's future behavior. Professionals construct themselves as agents in possession of the requisite knowledge and skills, able to offer advice to abusers on how to refrain from using violence in the future. In other words, they assist in the agency change, during which abusers acquire skills and competence they need to control their behavior.

The educating discourse, while it puts the professionals in the position of an active agent, also resembles the empowering discourse in that it assigns the final responsibility for change to the client himself. The professional merely offers tools for a change, which the client himself must then implement. In the informants' experience, not all clients understand their own role in this process of change; instead, some of them assume that it is the professional's task to bring about the change:

G8P1: Sometimes there are people, who want to get rid of that violence quickly, but it's a slow process.

G8P2: We often meet people, who say: "Take this problem away. You're a professional, could you do it like right now?" Well, that's what I hope for, too, when I go to see the dentist.

Mere understanding of the need for change is not enough: the client must, in addition, take responsibility for translating his understanding into action. The future is an essential aspect of the concept of prospective responsible agency. In this framework, to be an agent, an 
individual needs to be intentional: action is projection into the future, into a future that does not exist at the present. It is about changing reality so that it conforms to the set goals (Bratman, 2007). From the professional's point of view, the challenge lies in how these new ways of acting in the clients' future everyday life are to be implemented, without guidance from the professional:

G8P3: The challenge lies in the question of rooting this emerging change in the relationship. Like, how to transfer the control of one's violent impulses to their shared lives. It is a challenge that the professionals try to work with, like how to support the transfer of these learnt skills from the sessions to home.

Although the professionals help their clients to root this change in their lives, the responsibility for the future remains with the clients, if not sooner then when the counseling is over. The position of prospective responsibility requires that clients can act as independent agents, without guidance or supervision from anyone else.

\section{THE DIVISION OF RESPONSIBILITY IN ENDING IPV: PROBLEMS AND}

\section{POSSIBILITIES}

Through a discourse analysis of focus group discussion among social and health care professionals I identified four discourses on responsible agency in ending the vicious cycle of IPV: (1) making the victim responsible, (2) empowering the victim, (3) making the perpetrator responsible, and (4) educating the perpetrator. All four discourses place professionals and their clients in complementary - albeit not fixed - subject positions, in which one is the more active agent, and the other is the more passive agent in the problemsolving process. 
These complementary subject positions are most evident in the discourse of making the perpetrator responsible. In this discourse, the professional is placed in a powerful position to demand or even force the abuser to take both retrospective and prospective responsibility for IPV. In contrast to the discourse of making the perpetrator responsible, where the role of the professional is to actively pin the responsibility for IPV on the client, in the discourse of making the victim responsible the agency of professional is limited by the ideals of client autonomy and voluntarism. Because in this discourse the professionals do not perceive themselves as having any right to take initiative in violence intervention or to actively influence the client's choices, their role is narrowed down to offering the victims information.

Despite their apparent differences, these two discourses overlap and are interconnected in several ways. Although individual freedom to choose is respected in the discourse of making the victims responsible, professionals nevertheless end up assigning responsibility to their clients. In attempting to inculcate a retrospective sense of responsibility, professionals may position the victim as responsible for the life choices that expose her to IPV. When professionals hold the victim responsible in a prospective sense, they expect the victim to find the solution to the problem; and if the victim fails to make the "right choices", she is often seen as responsible for any repeat violence in the future. In this way, the discourse constructs the victim as the agent of her own liberation and, by implication, imprisonment as well (see also Dunn \& Powell-Williams, 2007).

Like the discourse of making the victim responsible, the discourse of making the perpetrator responsible has to deal with the contradictions caused by individualistic approaches to the problem of IPV. Although in this discourse the professionals appear to have a strong position in relation to their client as they may demand that the client takes responsibility, on closer scrutiny the position of the "commanding" professional is reduced to one of an agent seeking to promote genuine motivation and a true desire for change in the 
client. Indeed, in both of these discourses, there seems to be a contradiction between the avowed respect for individual free will and the position of the professional as a person demanding that others take responsibility. The professionals may try to motivate the victim and perpetrator to find a solution to the problem, but the acts of clients are nevertheless presumed to be based on free will or rational choices made by the clients themselves. This may make the professionals see violence intervention as an impossible task.

From the point of view of violence intervention, it is problematic whether individual autonomy - free will and intentionality - should have priority over preventing future violence. An alternative approach sees the responsible agency of clients - and the intentionality of action as an important attribute of it - from an intersubjective perspective. Responsible agency and projectivity, in particular, are neither radically individualistic nor narrowly voluntaristic: the formation of projects is always an interactive, culturally embedded process by which the social actors negotiate their paths towards the future, receiving their driving impetus from prevailing social standards and collectively agreed goals of action. Instead of defining responsible agency in terms of individual motivation, free will, and selfdetermination, we should see responsibility as formed in those social processes through which individuals affect each other (Barnes, 2009). This alternative approach emphasizes the responsibility of professionals and their role as active co-producers of the responsible agency of their clients in the process of ending IPV.

In my data, it emerged that the professionals engaged in violence intervention work take up active subject positions as the co-producers of responsible agency for their clients by emphasizing empowering and educational interventions. In the discourses of empowering the victim and educating the perpetrator, the client is, initially, placed at the receiving end of the professional help and guidance. However, both discourses end up returning active agency to the client by stressing the client's responsibility in future actions. Although the professional's 
roles as the activator of client agency and the motivator of the client's taking of responsibility are central at the beginning of the process, as the process continues the client's own activity in taking prospective responsibility across situations becomes increasingly important.

In the feminist critique of the empowerment and educational tendencies, these two discourses rely on therapeutic vocabularies that shift attention away from socio-cultural factors and towards the individuals. The empowerment of victims is defined as a personal project: by referring mainly to individual self-assert or the psychological experience of feeling powerful, it fails to take into account the structural, cultural and gendered context of power (Berns, 2009). This idea of empowerment centers attention on the victim's agency and ability to end the violence and, hence, it ends up placing the burden of prospective responsibility on female victims; and in so doing it absolves the male perpetrators from taking responsibility to end the cycle of IPV.

The discourse on educating the abuser, in turn, is based on therapeutic approaches to individual communication skills. When solving the problem of IPV in an interactional framework, there is a risk that the female victim will be put in the position of having to take responsibility not only for her own behavior but also that of her partner. The persistence of the emphasis on the responsibility of the victim may be due to the aspect mentioned by ThaparBjörkert and Morgan (2010): there has been no real attempt to challenge traditional genderrole beliefs that are more likely to attribute responsibility to the victim. Although evidence of the tendency to blaming the victims or "gendering the blame" (Berns, 2009) is scarce in my data, there nevertheless seems to be a strong propensity to shift the responsibility for ending the violence from the abusers to the victims. Putting this into a temporal framework, we could say that while my informants avoided assigning retrospective responsibility to the victims, they often ended up assigning prospective responsibility to them without problematizing the tendency towards "gendering the responsibility" 
Similarly, there seems to be a tendency to place the onus on the female victim on the level of national policies and discourses. Hearn and McKie (2010) claim that policies and services tend to focus women's agency, with abused women often being encouraged to leave the relationship and home, rather than on the acts of male abusers. Furthermore, Berns (2009) maintains that assigning the responsibility for solving the problem of IPV to the victim is inappropriate if our goal is to effectively work towards prevention of the problem. When the focus is on victims, the source of harm is generally ignored, resulting in very little public debate on why abusers abuse. If the sole focus of services is on helping victims after the violence has occurred, we will never make progress in reducing the amount of violence perpetrated.

Therefore, there are good reasons to suggest that the focus in violence intervention policies should be on perpetrators and, most importantly, on getting them to commit to prospective responsibility for stopping the vicious cycle of violence. In this article, the theoretical distinction between retrospective responsibility and prospective responsibility offers new insights on the temporal dimensions of the process of assigning responsibility for the problem. Violence intervention work is an endeavor that is future oriented; it should aim at finding means for change and supporting actions that would prevent future violence. In addition, it should be a collective endeavor. It is essential to emphasize the importance of the role of social and health care professionals' in promoting and supporting the intersubjective formation of responsible agency by the clients, particularly perpetrators. By focusing on the collective enhancement of prospective responsibility, the question of violence intervention can be transformed into one of violence prevention. 


\section{REFERENCES}

Baly, A.R. (2010). Leaving abusive relationships: Constructions of self and situation by abused women. Journal of Interpersonal Violence, 25, 2297-2315.

Barnes, B. (2000). Understanding Agency. Social Theory and Responsible Action. London: Sage.

Black, M.C. (2011). Intimate partner violence and adverse health consequences: implications for clinicians. American Journal of Medicine, 5, 428-439.

Berns, N. (2009). Framing the Victim. Domestic Violence, Media and Social Problems. London: Aldine Transaction.

Berns, N. \& Schweingruber, D. (2007). “When you're involved, it's just different”. Making sense of domestic violence. Violence Against Women, 13, 240-261.

Bratman, M.E. (2007). Structures of Agency. Oxford: Oxford University Press.

Busch, N. \& Valentine, D. (2000). Empowerment practice: A focus on battered women. Affilia, 15, 82-95.

Dunn, J.L. \& Powell-Williams, M. (2007). "Everybody makes choices": Victim advocates and the social construction of battered women's victimization and agency. Violence Against Women, 13, 977-1001.

Dutton M., Green B., Kaltman S., Roesch D., Zeffiro T. \& Krause E. (2006). Intimate Partner Violence, PTSD, and Adverse Health Outcomes. Journal of Interpersonal Violence, 21, 955-968.

Flood, M. \& Pease, B. (2009). Factors influencing attitudes to violence against women. Trauma, Violence \& Abuse, 10, 125-142.

Fox, K.A. \& Cook, C.L. (2011). Is knowledge power? The effects of a victimology course on victim blaming. Journal of Interpersonal Violence, 26, 3407-3427. 
Gee, P. (2010). An Introduction to Discourse Analysis: Theory and Method. London: Routledge.

Harre, R. (1995). Agentive discourse. In R. Harre \& P. Stearns (Eds.), Discursive psychology in practice (pp. 120-136). London: Sage.

Hearn, J. \& McKie, L. (2010). Gendered and social hierarchies in problem representation and policy processes: "Domestic violence" in Finland and Scotland. Violence Against Women, 16, 136-158.

Henning, K., Jones, A.R. \& Holdford, R. (2005). “I didn’t do it, but if I did I had a good reason": minimization, denial, and attributions of blame among male and female domestic female offenders. Journal of Family Violence, 20, 131-139.

Husso, M., Virkki, T., Notko, M., Holma, J., Laitila, A. \& Mäntysaari, M. (2012). Making sense of violence intervention in professional health care. Health and Social Care in the Community, 20, 347-355.

Kelley, M. (2005). Limits on patient responsibility. Journal of Medicine and Philosophy, 30, 189-206.

Kulkarni, S.J., Bell, H. \& Wylie, L. (2010). Why don't they follow through: Intimate partner survivors' challenges in accessing health and social services. Family \& Community Health, 33, 94-105.

Kulkarni, S.J., Bell, H. \& Rhodes, D.M. (2012). Back to basics: Essential qualities of service for survivors of intimate partner violence. Violence Against Women, 18, 85-101.

Lawson, D.M., Kellam, M., Quinn, J. \& Malnar, S.G. (2012). Integrated cognitive-behavioral and psychodynamic psychotherapy for intimate partner violent men. Psychotherapy, 49, 190-201.

Leisenring, A. (2006). Confronting "victim" discourses: The identity work of battered women. Symbolic Interaction, 29, 307-330. 
McCollum, E.E. \& Stith, S.M. (2008). Couples treatment for interpersonal violence: A review of outcome research literature and current clinical practices. Violence and Victims, 23, $187-201$.

Partanen, T., Wahlström, J. \& Holma, J. (2006) Loss of self-control as excuse in group therapy conversations for intimately violent men. Communication \& Medicine, 3, 171183.

Perez, S., Johnson, D.M. \& Wright, C.V. (2012). The attenuating effect of empowerment on IPV-related PTSD symptoms in battered women living in domestic violence shelters. Violence Against Women, 18, 102-117.

Powers, P. (2003). Empowerment as treatment and the role of health professionals. Advances in Nursing Science, 26, 227-237.

Rivara F., Anderson M., Fishman P., Bonomi A., Reid R. \& Carrell D. (2007). Healthcare utilization and costs for women with a history of intimate partner violence. American Journal of Preventive Medicine, 32, 89-96.

Robinson, R. (2010). Myths and stereotypes: How registered nurses screen for intimate partner violence. Journal of Emergency Nursing, 36, 572-577.

Schrock, D.P. \& Padavic, I. (2007). Negotiating hegemonic masculinity in a batterer intervention program. Gender \& Society, 21, 625-649.

Scott, K.R. \& Wolfe, D.A. (2000). Change among batterers: Examining men's success stories. Journal of Interpersonal Violence, 15, 827-842.

Shamai, M. \& Buchbinder, E. (2009). Control of the self: Partner-violent men's experience of therapy. Journal of Interpersonal Violence, 25, 1338-1362.

Sheehan, K.A., Thakor, S. \& Stewart, D. (2011). Turning points for perpetrators of intimate partner violence. Trauma, Violence \& Abuse, 13, 30-40. 
Stosny, S. (2005). Group treatment of intimate partner abusers. In G.L. Greif \& P.H. Ephross (Eds.) Group work with populations at risk (pp. 226-237). New York: Oxford University Press.

Sulkunen, P. (2010). Agency and power: The contractual illusion. European Journal of Cultural Studies, 13, 495-510.

Thapar-Björkert, S. \& Morgan, K.J. (2010). "But sometimes I think... they put themselves in the situation": Exploring blame and responsibility in interpersonal violence. Violence Against Women, 16, 332-59.

Turoldo, F. (2009). Responsibility as an ethical framework for public health intervention. American Journal of Public Health, 99, 1197-1202.

van Langehove, L. \& Harré, R. (2003). Introducing positioning theory. In R. Harré \& L. van Langenhove (Eds.) Positioning Theory: Moral Contexts of Intentional Action (pp.1431). Oxford: Blackwell.

Wallach, H.S. \& Sela, T. (2008). The importance of male batters' attributions in understanding and preventing domestic violence. Journal of Family Violence, 23, 655660.

Watson, G. (2004). Agency and Answearability. Oxford: Oxford University Press.

Yamawaki, N., Ochoa-Shipp, M., Pulsipher, C., Harlos, A. \& Swindler, S. (2012). Perceptions of domestic violence: The effects of domestic violence myths, victim's relationship with her abuser, and the decision to return to her abuser. Journal of Interpersonal Violence, 27, 3195-3212. 
Author biography

Tuija Virkki, Ph.D., is a senior researcher in the Department of Social Sciences and Philosophy at the University of Jyväskylä, Finland. She has published three monographs and more than twenty articles both in English and in Finnish. In her recent studies, she has analyzed the subjectivity of the female body, the interconnections between anger, aggressions and agency, and experiences of violence both in intimate relationships and in workplaces and organizations. Currently she is studying domestic violence intervention in social and health care institutions in a research project funded by the Academy of Finland. 